\title{
PENGARUH MARKETING MIX TERHADAP LOYALITAS KONSUMEN PERMEN SUSU
}

\author{
The Effect of Marketing Mix on the 'Permen Susu' Consumer's Loyality \\ Agus Santoso $^{1}$, Yandri Sudodo ${ }^{1}$, Muhammad Nur Fietroh ${ }^{1}$ \\ ${ }^{1}$ Program Studi Manajemen, Fakultas Ekonomi dan Bisnis, Universitas Teknologi Sumbawa \\ *) E-mail: agus.tamvan@gmail.com
}

\section{ABSTRACT}

This study aims to determine the effect of Marketing Mix on 'Permen Susu' consumer's loyality at the small and medium enterprises in Moyo Hilir. This research is designed as a quantitative study. Population in this research is Sumbawa's society who consume 'permen susu' regularly. Respondents were chosen by random sampling method to get 100 respondents. Analysis of the data is using linear multivariable regression which consist of validity test, reliability test, $t$ test, f test, determination test and test of classical assumption. The results revealed that 'product' variable has a positive and significant effect on 'permen susu' consumer's loyalty. Next, 'price' variable has positive and significant influence on 'permen susu' consumer's loyalty. 'Promotion' variable has positive and significant effect to 'permen susu' consumer's loyalty. Besides, 'location' variable has positive and significant influence on 'permen susu' consumer loyalty. Simultaniously, Marketing mix affects 'permen susu' consumer's loyalty with confidence level of $62,2 \%$ while the rest $37,8 \%$ influenced by other factors. It is recommended for the 'permen susu' or milk candy producers to consider marketing mix starategy, innovate products and intensify promotions and sales through proven effective social media.

Keywords: Marketing mix, Consumer's Loyalty, Permen Susu

\begin{abstract}
ABSTRAK
Penelitian ini bertujuan untuk mengetahui pengaruh Marketing Mix terhadap Loyalitas konsumen permen susu pada UMKM permen susu di kecamatan Moyo Hilir. Jenis penelitin ini adalah kuantitatif. Populasi dalam penelitian ini adalah masyarakat kecamatan Sumbawa, dalam menentukan sampel menggunkan random sampling dengan mengambil sampel dengan jumlah 100 orang responden. Analisis data yang digunakan adalah regresi linier berganda terdiri dari Uji validitas,reliabilitas uji t, uji f, uji determinasi dan Uji asumsi Klasik. Hasil penelitian menunjukkan bahwa: variabel produk berpengaruh positif dan signifikan terhadap loyalitas konsumen permen susu. Adapun variabel harga berpengaruh positif dan signifikan terhadap loyalitas konsumen permen susu. Variabel promosi berpengaruh positif dan signifikan terhadap loyalitas konsumen permen susu. Selanjutnya variabel lokasi berpengaruh positif dan signifikan terhadap loyalitas konsumen permen susu. Secara simultan, Marketing mix berpengaruh signifikan terhadap loyalitas konsumen dengan tingkat kepercayaan 62,2\% sedangkan sisanya 37,8\% di pengaruhi oleh factor lain di luar variabel yang di teliti. Disarankan bagi produsen permen susu untuk mempertimbangkan starategy marketing mix, melakukan inovasi produk dan mengintensifkan promosi dan penjualan melalui media sosial yang terbukti efektif.
\end{abstract}

Kata kunci: Marketing mix , Loyalitas Konsumen, Permen Susu

\section{Pendahuluan}

Indonesia mengalami krisis ekonomi tahun 1998 yang menyebabkan jatuhnya perekonomian nasional. Banyak usaha-usaha skala besar pada berbagai sektor mengalami stagnasi bahkan sampai terhenti aktifitasnya pada tahun 1998. Namun, Usaha Mikro, Kecil, dan Menengah (UMKM) dapat bertahan dan menjadi pemulih perekonomian ditengah keterpurukan akibat krisis moneter pada berbagai sektor ekonomi (Dani Danuar Tri .U 2013). Berdasarkan data sensus ekonomi Provinsi Nusa Tenggara Barat tercatat 598,7 usaha/perusahaan yang dimana 99,2\% adalah UKM.
Terdapat berbagai sentra UKM di Sumbawa, salah satunya adalah permen susu. Permen susu adalah makanan khas Sumbawa yang memanfaatkan kearifan lokal sumbawa. Permen susu awalnya terbuat dari susu kerbau karena alasan jumlah bahan baku susu kerbau yang terbatas, maka diganti dengan susu sapi.

Peremen susu di kemas dalam berbagai ukuran yang terkemas didalam kotak atau mika,dengan kisaran harga sebagai berikut: 
Tabel 1. Ukuran dan harga permen susu

\begin{tabular}{ccc}
\hline NO & UKURAN & HARGA \\
\hline 1 & 1000 gram & 120.000 \\
2 & 500 gram & 60.000 \\
3 & 250 gram & $30.000-45.000$ \\
4 & 100 gram & $12.000-15.000$ \\
\hline
\end{tabular}

Sumber: Data primer diolah

Berdasarkan data dari Dinas Koperasi jumlah penguasaha permen susu yang telah terdaftar namanya sebagai berikut:

Tabel 2. Nama dan lokasi UMKM Permen Susu

\begin{tabular}{|c|c|c|}
\hline No & Nama UMKM & Lokasi \\
\hline 1 & RISIKA & Desa Penyaring \\
\hline 2 & DINDA & Desa Penyaring \\
\hline 3 & $\begin{array}{l}\text { SELAMAT } \\
\text { GAMA }\end{array}$ & Desa Penyaring \\
\hline 4 & $\begin{array}{l}\text { HARAPAN } \\
\text { JAYA }\end{array}$ & Desa Penyaring \\
\hline 5 & AWARA & Desa Penyaring \\
\hline 6 & PENGRAJIN & Desa Penyaring \\
\hline 7 & UD.NAMUD & Desa Penyaring \\
\hline 8 & ALIVIA & Desa Penyaring \\
\hline 9 & ROSA & Desa Penyaring \\
\hline 10 & SALING BEME & Desa Penyaring \\
\hline
\end{tabular}

Dari data table diatas menunjukkan bahwa sentra pembuatan permen susu berada di Kecamatan Moyo Utara. Permen susu memiliki rasa yang manis dan gurih. Untuk mencari permen susu hanya dijumpai di beberapa toko, dan pedagang eceran di Kabupaten Sumbawa. Dalam perkembanganya tidak semua produk permen susu mengalami perubahaan signifikan dalam kemasan ataupun bentuk permen susu. Dari segi promosi permen susu dipromosikan melalui baik di pameran,dan media sosial yang di lakukan oleh beberapa produsen. Selama ini konsumen hanya mengenal permen susu sebagai oleh-oleh makanan khas Sumbawa dan camilan ketika hari raya. Mengembangkan Usaha mikro, kecil dan menengah dibutuhkan strategi untuk tetap bertahan dan berkembang di era ekonomi yang pesat, maka digunakan strategi Marketing Mix.

Berdasarkan latar belang di atas maka penulis melakukan penelitian dengan judul "Pengaruh marketing mix terhadap loyalitas konsumen permen susu".

Berdasarkan penejelasan di atas, maka dapat di rumuskan tujuan penelitian sebagai berikut :

1. Untuk mengetahui pengaruh produk terhadap Loyalitas konsumen permen susu
2. Untuk mengetahui pengaruh promosi terhadap loyalitas konsumen permen susu

3. Untuk mengetahui pengaruh harga terhadap loyalitas konsumen permen susu

4. Untuk mengetahui pengaruh tempat terhadap loyalitas konsumen permen susu

5. Untuk mengetahui pengaruh marketing mix terhadap Loyalitas konsumen permen susu

\section{Metode Penelitian}

Menurut Siregar, (2012:2) "Penelitian adalah penyaluran rasa ingin tahu manusia terhadap masalah seperti memeriksa, mengusut, menelaah, dan mempelajari secara cermat serta memformulasikan hipotesis sehingga diperoleh sesuatu seperti mencapai kebenaran, memperoleh jawaban atas masalah, pengembangan ilmu pengetahuan, dan sebagainya".

Dalam Penelitian ini, penulis mengunakan kuantitatif, dimana penelitian ini menggunakan metode survey dengan teknik analisis korelasional untuk mengetahui kaitan antara variabel terikat dan variabel bebas, atau lengkapnya selfadministered survey adalah pengumpulan data yang menggunakan instrument kuesioner dan wawancara untuk mendapatkan tanggapan dari responden.

Data yang digunakan dalam penelitian ini adalah data primer, yaitu data yang bersumber dari penyebaran kuesioner terhadap masarakat kecamatan Sumbawa yang telah membeli atau mengkonsumsi permen susu, untuk mengetahui apakah factor Marketing Mix mempengaruhi loyalitas konsumen permen susu.

Teknik analisi data yang di gunkan yaitu:

a. Observasi

Peneliti mengunakan observasi tak berstruktur yang merupakan observasi dimana pengamat melakukan pengamatan secara bebas

b. Kuesioner

Merupakan teknik pengumpulan data yang dilakukan dengan cara memberi seperangkat pertanyaan atau pernyataan tertulis kepada responden untuk dijawab (Sugiyono : 2014). Kuesioner yang telah dibuat kemudian disebar dikalangan masyarakat kecamatan Sumbawa.

c. Wawancara

Yaitu pengumpulan data dengan melakukan wawancara langsung terhadap responden, Penjual dan produsen permen susu dengan tujuan untuk mengetahui gambaran secara umum mengenai perkembangan permen susu. 


\section{d. Studi Pustaka}

Studi pustaka dilakuakan dengan mengambil data dan literature dari sumber yang dianggap bisa memberikan informasi dalam penelitian ini.

\section{Lokasi penelitian}

Lokasi penelitian dilakukan di Kecamatan Sumbawa Besar. Penelitian dilaksnakan pada bulan Juli 2017.

\section{Variabel}

Menurut Sugiyono (2010:59), variabel merupakan suatu atribut atau sfat atau nilai dari orang, objek, atau kegiatan yang mempunyai variasi tertentu yang di tetapkan oleh peneliti untuk dipelajari dan ditarik kesimpulanya. Terdapat dua varibel di dalam penelitian yaitu,Variabel independent dalam penelitian ini adalah marketing mix. Dalam penelitia ini variabel dependent adalah loyaitas konsumen

\section{Hasil dan Pembahasan}

\section{Uji Validitas}

Sebelum data yang dikumpulkan, diolah dan di analisis lebih lanjut, maka diperlukan uji Validitas. Menurut imam ghozali dalam Irsad.z (2010 : 64) uji validitas di gunkan untuk mengukur sah atau validnya suatu data kuesioner. Uji validitas dilakukan untuk membandingkan $r$ hitung dengan $r$ tabel. Penulis melakukan penyebaran kuesioner terhadap 100 responden.Untuk mendapat data yang valid maka penulis melakukan uji validitas dengan melakukan try out kepada 45 responden. Dengan 20 butir pertanyaan, dibagi menjadi 5 variabel yaitu Marketing Mix (produk, harga, promosi, lokasi) dan variabel loyalitas konsumen. Perhatikan tabel 3 untuk mengetahui hasil uji validitas data yang menggunakan kriteria:

$\mathrm{R}_{\text {hitung }}>\mathrm{Rt}_{\mathrm{abel}}$ dengan nilai signifikansi $5 \%=$ valid

$\mathrm{R}_{\text {hitung }}<\mathrm{Rt}_{\text {abel }}$ dengan nilai signifikansi 5\% = tidak valid

\section{Uji Reliabilitas}

Reliaibitas adalah sejauh mana hasil pengukuran dapat dipercaya atau diandalkan. Keandalan disini bisa bearti beberapa kalipun variabel-variabel pada kuisisoner tersebut ditanyakan kepada responden maka hasilnya tidak menyimpang terlalu jauh dari rata-rata jawaban responden (Wijaya, 2011:91).

Pengujian reliabilitas dalam penelitian ini untuk menunjukkan konsistensi suatu alat pengukur dalam penelitian dengan nilai alpha croncbach karena menggunakan data jenis likert. Peneliti mengunakan metode alpha croncbach dengan signifikansi 0,5. Jika nilai alpha croncbach suatu variabel lebih besar dari 0,5 maka pertanyaan dinyatakan reliabel. Jika nilai alpha croncbach suatu variabel lebih kecil dari 0,5 maka pertanyaan dinyatakan tidak reliable. Adapun hasil dari uji reliabilitas dapat dilihat pada tabel 4.

Tabel 3. Hasil Uji Validitas

\begin{tabular}{|c|c|c|c|c|}
\hline Variabel & $\begin{array}{c}\text { Jumlah } \\
\text { pernyataan }\end{array}$ & $\begin{array}{c}R \\
\text { tabel } \\
(5 \%) \\
\end{array}$ & $\begin{array}{c}\mathbf{R} \\
\text { hitung }\end{array}$ & Keterangan \\
\hline \multirow[t]{4}{*}{ Produk } & P1 & 0,294 & 0,829 & Valid \\
\hline & $\mathrm{P} 2$ & 0,294 & 0,628 & Valid \\
\hline & P3 & 0,294 & 0,535 & Valid \\
\hline & $\mathrm{P} 4$ & 0,294 & 0,845 & Valid \\
\hline \multirow[t]{4}{*}{ Harga } & $\mathrm{P} 1$ & 0,294 & 0,808 & Valid \\
\hline & P2 & 0,294 & 0,480 & Valid \\
\hline & P3 & 0,294 & 0,822 & Valid \\
\hline & P4 & 0,294 & 0,749 & Valid \\
\hline \multirow[t]{5}{*}{ Promosi } & P1 & 0,294 & 0,303 & Valid \\
\hline & $\mathrm{P} 2$ & 0,294 & 0,557 & Valid \\
\hline & P3 & 0,294 & 0,438 & Valid \\
\hline & P4 & 0,294 & 0,312 & Valid \\
\hline & P5 & 0,294 & 0,427 & Valid \\
\hline \multirow[t]{3}{*}{ Lokasi } & $\mathrm{P} 1$ & 0,294 & 0,540 & Valid \\
\hline & P2 & 0,294 & 0,772 & Valid \\
\hline & P3 & 0,294 & 0,779 & Valid \\
\hline \multirow[t]{4}{*}{ Loyalitas } & $\mathrm{P} 1$ & 0,294 & 0,601 & Valid \\
\hline & $\mathrm{P} 2$ & 0,294 & 0,765 & Valid \\
\hline & P3 & 0,294 & 0,660 & Valid \\
\hline & $\mathrm{P} 4$ & 0,294 & 0,826 & Valid \\
\hline
\end{tabular}

Sumber: Data Primer diolah 2017

Tabel 4. Hasil uji Reliabilitas

\begin{tabular}{llll}
\hline Variabel & $\begin{array}{c}\text { Cronbach's } \\
\text { alpha }\end{array}$ & $\begin{array}{c}\text { r tabel } \\
\mathbf{5 \% ( 4 5 )}\end{array}$ & Keterangan \\
\hline Produk & 0,786 & 0,294 & Reliabel \\
Harga & 0,782 & 0,294 & Reliabel \\
Promosi & 0,547 & 0,294 & Reliabel \\
Lokasi & 0,772 & 0,294 & Reliabel \\
Loyalitas & 0,781 & 0,294 & Reliabel \\
\hline \multicolumn{2}{l}{ Sumber: Data Primer Diolah 2017}
\end{tabular}

\section{Uji asumsi Klasik}

Asnawi, (2011 : 176)Untuk mendapat nilai pemeriksa yang tidak bias dan efisien (Best Linear Unbias Estimator/BLUE) dari suatu persmaan regresi berganda dengan metode kuadrat kecil (least squares)

\section{- Uji Normalitas}

Data bertipe skala pada umumnya berdistribusi normal, untuk membuktikan hal tersebut penulis melakukan uji normalitas. Menurut Gozali (2009 : 147) Uji normalitas bertujuan apakah dalam model regresi variabel dependen (terikat) dan variabel independen (bebas) mempunyai kontribusi atau tidak. 


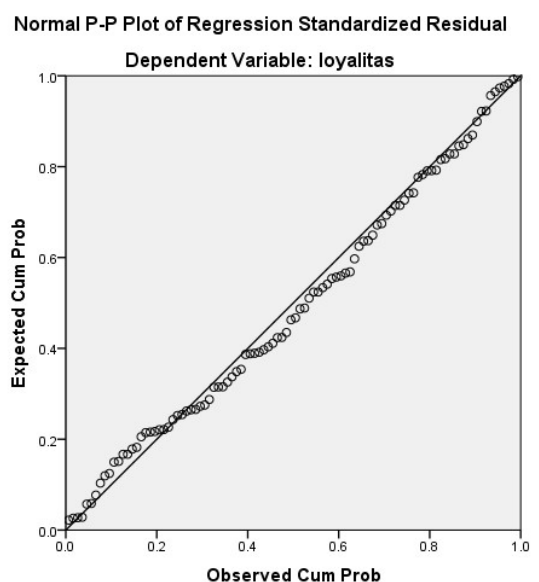

Gambar 1. Hasil Uji Normalitas (data primer diolah, 2017)
Dari output P - P Plot terlihat bahwa sebaran data memebentuk atau mengikuti garis linier, sehingga dapat dikatakan bahwa data berditribusi normal.

\section{- Uji Multikolinieritas}

Uji Multikolinearitas digunakan untuk mengatahui ada atau tidaknya variabel independen yang memiliki kemiripan dengan variable independen lainya dalam satu model. Kemiripan varibael independen akan menyebabkan korelasi yang antar variabel independen lain.

Hasil uji multikolinieritas menunjukkan bahwa nilai VIF tidak lebih besar dari 10 dan nlai tolerance lebih besar dari 0,10 dan nilai tolerance lebih besar 0,10 artimya tidak terjadi multikolinieritas pada masing masing variabel. Lebih jelasnya, perhatikan 5 mengenai hasil uji multikolinieritas berikut.

Tabel 5. Hasil uji Multikolinieritas

\begin{tabular}{|c|c|c|c|c|c|c|c|}
\hline \multirow[b]{2}{*}{ Model } & \multicolumn{2}{|c|}{$\begin{array}{c}\text { Unstandardized } \\
\text { Coefficients }\end{array}$} & \multirow{2}{*}{$\begin{array}{c}\begin{array}{c}\text { Standardized } \\
\text { Coefficients }\end{array} \\
\text { Beta } \\
\end{array}$} & \multirow[b]{2}{*}{$\mathrm{t}$} & \multirow[b]{2}{*}{ Sig. } & \multicolumn{2}{|c|}{ Collinearity Statistics } \\
\hline & $\mathrm{B}$ & Std. Error & & & & Tolerance & VIF \\
\hline (Constant) & 2.652 & 1.083 & & 2.448 & .016 & & \\
\hline produk & .220 & .095 & .229 & 2.319 & .023 & .408 & 2.450 \\
\hline harga & .182 & .089 & .200 & 2.044 & .044 & .417 & 2.400 \\
\hline promosi & .169 & .066 & .207 & 2.562 & .012 & .612 & 1.635 \\
\hline lokasi & .476 & .114 & .328 & 4.176 & .000 & .644 & 1.554 \\
\hline
\end{tabular}

\section{- Uji Heteroskedastisitas}

Uji heteroskedastisitas digunakan untuk menguji terjadinya perbedaan variance residual satu priode pengamatan ke priode pengamatanlainya. Pada heteroskedastisitas, kesalahan yang terjadi tidak secara acak tetapi menunjukkan hubungan yang sitematis besarnya atau lebihnya variabel. Berdasarkan data yang telah di olah, maka hasil Scatterplot seperti gambar di bawah ini:

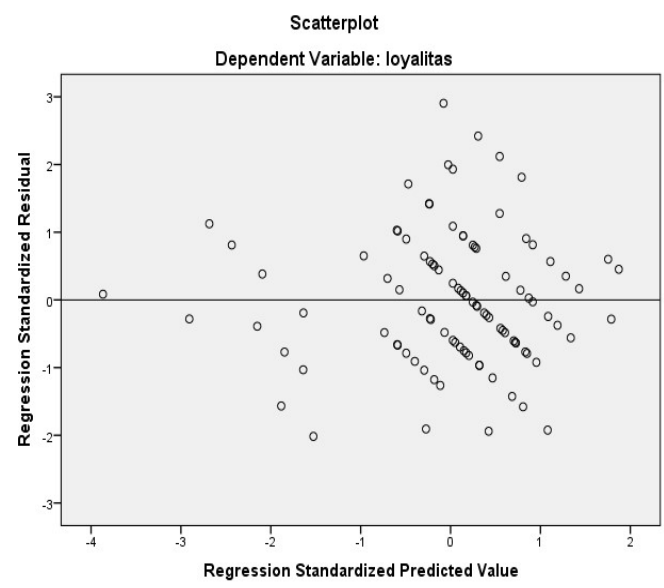

Gambar 2. Hasil uji heteroskedastisitas (data primer diolah, 2017). 
Jika data menyebar pada garis nol secara acak maka data dapat dikatakan bebas dari masalah heteroskedenitas, pada model regresi

\section{Analisi Regresi Linier Berganda}

Analisis regresi linier berganda digunakan untuk mengetahui pengaruh antara variabel independen dengan variabel dependen. Hasil uji regresi berganda dapat dilihat pada tabel berikut :

Tabel 6. Hasil Regresi linier berganda

\begin{tabular}{lcrc}
\hline \multirow{2}{*}{ Model } & \multicolumn{2}{c}{ Unstandardized Coefficients } & $\begin{array}{c}\text { Standardized } \\
\text { Coefficients }\end{array}$ \\
\cline { 2 - 4 } (Constant) & \multicolumn{1}{c}{ B } & \multicolumn{1}{c}{ Std. Error } & Beta \\
\hline Produk & 2.652 & 1.083 & \\
Harga & .220 & .095 & .229 \\
Promosi & .182 & .089 & .200 \\
Lokasi & .169 & .066 & .207 \\
\hline Sumber: Data primer diolah 2017 & .114 & .328 \\
\hline
\end{tabular}

Menurut Riduwan dan Akdim dalam Dengkeng (2012) sebagai berikut:

Dengan persmaan sebagai berikut:

$\mathrm{Y}=\mathrm{a}+\mathrm{X} 1 . \mathrm{b} 1+\mathrm{X} 2 . \mathrm{b} 2+\mathrm{X} 3 . \mathrm{b} 3+\mathrm{X} 4 . \mathrm{b} 4+\mathrm{e}$

Berdasarkan hasil yang diperoleh dari koefisien regresi diatas, maka dibuat persamaan berikut :

$\mathrm{Y}=2.652+0,220_{-}+0,182+0,169+0,169+0,476$

Dari persamaan diatas dapat diakatakan variabel X1 mempunyai pengaruh sebesar 0,220 terhadap variabel $\mathrm{Y}$, variabel X2 mempunyai pengaruh sebesar 0,182 terhadap variabel $\mathrm{Y}$, variabel X3 mempunyai pengaruh sebesar 0,169 terhadap variabel $\mathrm{Y}$ dan variabel $\mathrm{X} 4$ mempunyai pengaruh sebesar 0,476 terhadap variabel
Y. Setiap kenaikan X1 sebesar 0,220 maka mempunyai pengaruh sebanyak $1 \%$ terhadap variabel $\mathrm{Y}$, . Setiap kenaikan X2 sebesar 0,182 maka mempunyai pengaruh sebanyak $1 \%$ terhadap variabel Y, . Setiap kenaikan X3 sebesar 0,169 maka mempunyai pengaruh sebanyak $1 \%$ terhadap variabel $\mathrm{Y}$, dan . Setiap kenaikan X4 sebesar 0,476 maka mempunyai pengaruh sebanyak $1 \%$ terhadap variabel $\mathrm{Y}$.

\section{- Hasil Uji Determinasi (Adjusted $\mathbf{R}_{2}$ )}

Menurut Ghazali (2019 : 87) untuk menentukan seberapa besar variabel independen dapat menjelaskan variabel dependen, maka perlu diketahui nilai koefisien determinasi (Adjusted $\mathrm{R}_{2}$ ). Hasil uji determinasi (Adjusted $\mathrm{R}_{2}$ ) sebagai berikut :

Tabel 7. Model Summary

\begin{tabular}{cccccc}
\hline Model & R & R Square & $\begin{array}{c}\text { Adjusted R } \\
\text { Square }\end{array}$ & $\begin{array}{c}\text { Std. Error of } \\
\text { the Estimate }\end{array}$ & $\begin{array}{c}\text { Durbin- } \\
\text { Watson }\end{array}$ \\
\hline 1 & .789 & .622 & .606 & 1.187 & 1.566 \\
\hline
\end{tabular}

Sumber: Data primer diolah 2017

Berdasarakan output di atas diketahui nilai $\mathrm{R}$ Squer 0,622 .Hal ini mengandung arti bahwa pengaruh variabel $\mathrm{X} 1, \mathrm{X} 2, \mathrm{X} 3$, dan $\mathrm{X} 4$ terhadap variabel $\mathrm{Y} 62,2 \%$, sedangkan sisanya $37,8 \%$ di pengaruhi oleh faktor lain di luar variabel yang di teliti.

\section{Pengujian Hipotesis}

\section{- Hasil Uji F (Pengujian Secara Simultan)}

Uji ini adalah untuk mengetahui apakah pengaruh masing-masing variabel bebas terhadap variabel terikat. Hasil uji F dapat dilihat sebagai berikut:

Kriteria pengujian :

a. Jika nilai $\operatorname{sig}<0,05$, atau $\mathrm{F}$ hitung $>\mathrm{F}$ tabel maka terdapat pengaruh variabel $\mathrm{X}$ secara simultan terhadap variabel $\mathrm{Y}$ 
b. Jika nilai sig $>0,05$, atau $\mathrm{F}$ hitung $<\mathrm{F}$ tabel maka tidak terdapat pengaruh variabel $\mathrm{X}$ secara simultan terhadap variabel Y

\begin{tabular}{lccccc}
\multicolumn{2}{l}{ Tabel 8. Hasil Uji F } & & & & \\
& Sum of & \multicolumn{4}{c}{ Mean } \\
Model & Squares & df & Square & F & Sig. \\
\hline Regression & 220.352 & 4 & 55.088 & 39.12 & $.000^{\text {b }}$ \\
& & & & 6 & \\
Residual & 133.758 & 95 & 1.408 & & \\
Total & 354.110 & 99 & & & \\
\hline
\end{tabular}

Data Primer 2017

Berdasarkan output di atas diketahui nilai simultani untuk pengaruh nilai X1, X2, X3, dan X4 terhadap Y adalah sebesar $0,000<0,05$ dan nilai $F$ hitung 39.126 $>$ F tabel 2.47 sehingga dapat disimpulkan terdapat penagaruh X1, X2, X3, dan X4 secara simultan terhadap Y.

\section{- Uji t (Pengujian Secara Parsial)}

Uji t bertujuan untuk mengetahui variabel $\mathrm{X}$ terhadap variabel Y secara individual.

Kriteria pengujian :

a. Jika nilai sig $<0,05$ atau thitung $>\mathrm{t}$ tabel maka terdapat pengaruh variabel $\mathrm{X}$ terhadap $\mathrm{Y}$

b. Jika nilai sig $>0,05$ atau $t$ hitung $<\mathrm{t}$ tabel maka tidak terdapat pengaruh variabel $\mathrm{X}$ terhadap $\mathrm{Y}$

Tabel 9. Hasil Uji-t

\begin{tabular}{|c|c|c|c|c|c|}
\hline \multirow[b]{2}{*}{ Model } & \multicolumn{2}{|c|}{$\begin{array}{c}\text { Unstandardized } \\
\text { Coefficients }\end{array}$} & \multirow{2}{*}{$\begin{array}{c}\text { Standardized } \\
\text { Coefficients }\end{array}$} & \multirow[b]{2}{*}{$\mathrm{t}$} & \multirow[b]{2}{*}{ Sig. } \\
\hline & B & Std. Error & & & \\
\hline (Constant) & 2.652 & 1.083 & & 2.448 & .016 \\
\hline Produk & .220 & .095 & .229 & 2.319 & .023 \\
\hline Harga & .182 & .089 & .200 & 2.044 & .044 \\
\hline Promosi & .169 & .066 & .207 & 2.562 & .012 \\
\hline Lokasi & .476 & .114 & .328 & 4.176 & .000 \\
\hline
\end{tabular}

Sumber: Data primer diolah 2017

a. Pengaruh Produk terhadap Loyalitas konsumen

Diketahui nilai sig untuk X1 terhadap Y adalah sebesar $0,023<0,05$ dan nilai t hitung $2.319>$ 1.988 sehingga dapat disimpulkan bahwa pengaruh secara signifikan antara variabel X1 (produk) terhadap variabel Y ( loyalitas )

b. Pengaruh Harga terhadap Loyalitas konsumen

Diketahui nilai sig unutk X2 terhadap Y adalah sebesar $0,044<0,05$ dan nilai t hitung $2.044>$ 1.988 sehingga dapat disimpulkan bahwa terdapat pengaruh secara signifikan antara variabel X2 ( harga ) terhadap variabel Y ( loyalitas ) c. Pengaruh Promosi terhadap Loyalitas konsumen

Diketahui nilai sig unutk X3 terhadap Y adalah sebesar $0,012<0,05$ dan nilai thitung $2.562>$ 1.988 sehingga dapat disimpulkan terdapat pengaruh secara signifikan antara variabel X3 ( promosi ) terhadap variabel Y ( loyalitas )

d. Pengaruh Lokasi terhadap Loyalitas konsumen

Diketahui nilai sig unutk X4 terhadap Y adalah sebesar $0,000<0,05$ dan nilai thitung $4.176>$ 1.988 sehingga dapat disimpulkan bahwa terdapat pengaruh secara signifikan antara variabel X4 ( promosi ) terhadap variabel Y ( loyalitas ). 


\section{Kesimpulan}

Berdasarkan hasil penelitian dapat disimpulkan bahwa variabel produk berpengaruh positif dan signifikan terhadap loyalitas konsumen permen susu. Adapun variabel harga berpengaruh positif dan signifikan terhadap loyalitas konsumen permen susu. Variabel promosi berpengaruh positif dan signifikan terhadap loyalitas konsumen permen susu. Selanjutnya variabel lokasi

berpengaruh positif dan signifikan terhadap loyalitas konsumen permen susu. Secara simultan, Marketing mix berpengaruh signifikan terhadap loyalitas konsumen dengan tingkat kepercayaan $62,2 \%$ sedangkan sisanya $37,8 \%$ di pengaruhi oleh factor lain di luar variabel yang di teliti.

Berdasarkan kesimpulan tersebut, penulis menyarankan kepada produsen permen susu untuk mempertimbangkan starategy marketing mix, melakukan inovasi produk dan mengintensifkan promosi dan penjualan melalui media sosial yang terbukti efektif guna meningkatkan hasil penjualan.

\section{Daftar Pustaka}

Asnawi, Nur dan Masyuhi (2011). Metodologi Riset Manajemen Pemasaran. Malang : UIN - Maliki Press.

Dengkeng, Sangkaraja A,.(2012). 'Pengaruh bauran pemasaran terhadap loyalitas konsumen kartu prabayar simpati PT.TELKOMSEL di Makassar'. Skripsi, Makassar : Program Persyaratan Studi guna Memeperoleh Gelar Sarjana Ekonomi Kepada Fakultas Ekonomi Dan Bisnis Universitas Hasanudin Makassar

Siregar, Sofyan (2012). Metode Penenlitian Kuantitatif. Jakarta : PT.Fajar Interpratama Mandiri.

Sugiyono, (2013). Metode Penelitian Kuantitatif Kualitatif dan R\&D. Bandung : Alfabeta

Wijaya, T. (2011). Manajemen Kualitas Jasa. Jakarta : PT Indeks. 